\title{
Application of Error Correction Model in Assessing the Impact of Macroeconomic Variables on Stock Market Performance in Nigeria
}

\author{
Fatoki Olayode, Adeleye Najeem Friday ${ }^{*}$, Afolabi Nosimot Omowunmi \\ Department of Statistics, School of Pure and Applied Science, Ogun State Institute of Technology, Igbesa, Ogun State, Nigeria \\ Email address: \\ fatoki_olayode@yahoo.com (F. Olayode), leyinton@yahoo.com (A. N. Friday), nasimotafolabi@gmail.com (A. N. Omowunmi) \\ ${ }^{*}$ Corresponding author
}

To cite this article:

Fatoki Olayode, Adeleye Najeem Friday, Afolabi Nosimot Omowunmi Application of Error Correction Model in Assessing the Impact of Macroeconomic Variables on Stock Market Performance in Nigeria. International Journal of Data Science and Analysis.

Vol. 7, No. 3, 2021, pp. 69-75. doi: 10.11648/j.ijdsa.20210703.13

Received: February 26, 2020; Accepted: March 18, 2020; Published: May 14, 2020

\begin{abstract}
The objective of this paper is to investigate the relationships between some selected macroeconomic variables and stock market returns in Nigeria. Time series data on macroeconomic variables were collected from Central Bank of Nigeria (CBN) annual statistical bulletin 2018 covering between years 1981 to 2018. The error correction model (ECM) was used to show the strength of relationship between the macroeconomic variables and stock market performance. The result of the coefficients of macroeconomic variables are negative and positive values and also significant and insignificant. Hence, there is disequilibrium in the long run and must be corrected. The coefficient of parameters estimates for short run for return and gross domestic product at lag 1 are positive while values of crude oil prices, interest rate and inflation rate at lag 1 are negative. Hence, there is short run dynamic changes in crude oil prices, interest rate and inflation rate could lead to negative changes in stock market performance. The ECM coefficient is -0.80 suggesting that any disequilibrium can be corrected at the speed or rate of 80 percent within a year. In view of this, there is long run dynamic influence running from macroeconomic variables to stock market performance in Nigeria.
\end{abstract}

Keywords: Crude Oil Prices, Inflation Rate, Interest Rate, Gross Domestic Product (GDP), Stock Market Return, Error Correction Model (ECM), Nigeria

\section{Introduction}

The issue of stock market performance and the relationships between macroeconomic indicators has been a great concern to researchers, individual and portfolio managers who manage the investments of investors over the years.

There has being a recent decline observed in the Nigerian stock market, many scholars have investigated the effectiveness of monetary policies in order to improve the performance of the Nigerian stock market. Stabilizing and maintaining the financial system remains the main objective of the Central Bank of Nigeria (CBN).

Macroeconomic variables that influence stock market returns have been documented in recent finance literature without a consensus on their appropriateness as regressors.
This is confirmed by $[5,14,11]$.

This paper work aim at providing empirical evidences regarding the linkage between stock market and some selected macroeconomic variables in Nigeria using ECM.

The rest of the paper is organized as follows: section two reviews some relevant literature for the study, the materials and methods were presented in section three, results and discussion in section four and the section five present the conclusion and recommendations.

\section{Literature Review}

Empirical Literature

Several empirical studies have been conducted to validate whether macroeconomic variables has a favorable impact or otherwise on stock market index. Evidences from various 
researchers are reviewed in this study in order to get an adequate and better knowledge of the effect of macroeconomic variables on stock market index in both developed and developing economies.

The impact of several macroeconomic variables on stock markets in both developed and emerging economies [3]. Majority of these studies posit that macroeconomic variables have significant influence on stock market returns and suggest also the existence of a long-run relationship between these macroeconomic variables and stock prices or returns.

The influence of macroeconomic policy on stock returns in Nigeria capital market [2]. The study adopted Error correction modeling techniques that is based on estimation of both short and long run dynamics in the endogenous model. Results from the estimated models reveals that macroeconomic policy relating to aggregate economic activity (measured by GDP), broad money supply (M2), interest rate (INT) and consumer price index (CPI) are the most important macroeconomic factors explaining stock market returns in Nigeria.

The performance of arbitrage pricing theory (APT) in the Nigerian stock exchange using monthly data from 2000 to 2004, they utilized three macroeconomic variables (inflation, exchange rate and market capitalization). Using the ordinary least square (OLS) method, they found that there is no significant effect of these macroeconomic variables on stock returns in Nigeria [10].

The impact of Macroeconomic variables on stock market index in Brazil, Russia, India, China and South Africa [9]. He employed the Exponential GARCH model to study the impact of various economic variables that cause fluctuation in South Africa's stock market index. Findings of the study were that index of South Africa stock market has positive relation with growth in real GDP, US market index and the ratio of M3 money supply to GDP but has the negative relation with government deficit to GDP ratio, the domestic real interest rate and the inflation rate, the nominal effective exchange rate and the U.S. government bond yield.

The impact of macroeconomic variables on Average share price (ASP) and goes further to determine whether changes in macroeconomic variables explain movements in stock prices in Nigeria [4]. Various econometric analyses such as Augmented Dickey Fuller (ADF) test, Granger causality test, Johansen Co-integration test and Error Correction method (ECM) were employed on time series data from 1986 to 2007. The results revealed that a weak relationship exists between ASP and macroeconomic variables.

The impact of macroeconomic variables on Bombay stock exchange (BSE) [18]. The explanatory variables included in study were inflation rate, foreign exchange reserves, exchange rates and gold prices. Explained variable was the stock prices of BSE. Simple regression analysis had been applied to study the relation. Results of the study revealed that exchange rates have high negative correlation with stock prices; inflation rate has low negative correlation with stock prices and does not affect the stock prices. Foreign exchange reserves have positive correlation while the gold prices have moderate correlation with stock prices.

The impact of real GDP, inflation rate and interest rates (independent variables) on stock market returns (dependent variable) in Nigeria [7]. They applied multiple regression analysis technique for their analysis comprising ten years longitudinal data of the said variables. The results of the study showed that there is significant relationship among these variables. Increase in inflation and interest rates adversely affect the stock market returns whereas there is positive relation between real GDP and stock market returns. About $95.6 \%$ of the variations in stock market returns were explained by real GDP, inflation rate and interest rates.

The relationship between oil prices and stock markets in Gulf Corporation Council (GCC) countries [17]. They use data sets with weekly and monthly frequency for two periods: June 7, 2005 - October 21, 2008 and January 1996 December 2007, respectively. Interestingly, they provide strong statistical evidence that the causal relationship is consistently bi-directional for Saudi Arabia, suggesting that, investors in world oil markets should consider changes in the Saudi stock market as these changes significantly affect oil prices.

The influence that macroeconomic variables had on the Ghanaian stock market (represented by the Databank Stock Index) [1]. They concluded that the stock market in Ghana was significantly influenced by macroeconomic forces such as the interest rate, inflation, foreign direct investment and the exchange rate. The results of the co-integration test showed that treasury bills (the proxy for short-term interest rates) had a negative and significant relationship to stock price returns, while foreign direct investment had a positive and significant relationship. Inflation and exchange rates have a negative but insignificant relationship to stock market returns.

The relationship between the US stock price index and six macroeconomic variables, industrial production, money supply, Treasury bill rate, government bond rate, inflation and Japanese Yen/US Dollar exchange rate over the period 1975-1999 [16]. They observed that the stock prices negatively related to the long term interest rate and positively related to money supply, industrial production, inflation, exchange rate and short term interest rate.

Upon examining the relationships between stock market capitalization and interest rate [15]; find that prevailing interest rate exerts a positive influence on stock market capitalization rate. Their study also reveal that government development stock rate exerts a negative influence on stock market capitalization rate and that prevailing interest rate exerts negative influence on government development stock rate.

\section{Materials and Methods}

\subsection{Data Description and Source}

The sample period runs from 1981 to 2018 , to allow for a wide range of stability test. The data were collected on annual basis from the Central Bank of Nigeria (CBN) statistical bulletin. The variables used in this work includes 
stock market returns, crude oil prices, inflation rate, interest rate and gross domestic product (GDP).

\subsection{Model Specification}

Given a linear function with the following structure:

$$
\operatorname{Re} t_{t}=\beta_{0}+\beta_{1} C O I L+\beta_{2} G D P+\beta_{3} I N F+\mu_{t}
$$

Where: Ret represents stock market returns, COILS represent crude oil prices, GDP represents gross domestic product, INT represents interest rate, INF represents inflation rate, $\beta s$ represents the parameters to be estimated, $\mu_{t}$ represents the error term controlling for unit-specific residual in the model. The returns are computed using annual market capitalization through continuous compounding formula. The formula thus adopted is displayed below

$$
\operatorname{Re} t_{t}=\left[\log \left(P_{t}\right)-\log \left(P_{t-1}\right)\right]
$$

Assuming that the variables in equation (3.1), is not well behaved, this can be rewrite as:

$$
\begin{aligned}
& \Delta \operatorname{Re} t_{t}=\beta_{0}+\beta_{1}\left(\Delta \operatorname{COIL}_{t-i}\right)+\beta_{2}\left(\Delta G D P_{t-i}\right) \\
& +\beta_{3}\left(\Delta I N F_{t-i}\right)+\mu_{t}
\end{aligned}
$$

Where: $\Delta$ represents difference operator, $\beta_{i}$ represents parameters to be estimated, $t-i$ represents unknown lags to be estimated, $\mu_{t}$ represent the error term. It assumes that all the variables are well behaved; otherwise equation (3.3) is reformulated to:

$$
\begin{aligned}
& \Delta^{k_{0}} \operatorname{Re} t_{t}=\beta_{0}+\beta_{1}\left(\Delta^{k_{1}} C O I L_{t-i}\right)+\beta_{2}\left(\Delta^{k_{2}} G D P_{t-i}\right) \\
& +\beta_{3}\left(\Delta^{k_{3}} I N T_{t-i}\right)+\beta_{4}\left(\Delta^{k_{4}} I N F_{t-i}\right)+\mu_{t}
\end{aligned}
$$

Where: $\mathrm{K}$ represents order of differencing, $\mathrm{K}_{0}$ is not equal to $\mathrm{K}_{1}, \mathrm{~K}_{2}, \mathrm{~K}_{3}$, and $\mathrm{K}_{4}$. Else if $\mathrm{K}_{0}$ is equal to any of $\mathrm{K}_{1}, \mathrm{~K}_{2}, \mathrm{~K}_{3}$, and $\mathrm{K}_{4}$, then the study shall investigate the presence of a cointegration amongst the variables. If the residuals are stationary and a long run relationship is established, then the parameters will thus be suitably estimated by introducing an error correction mechanism (ECM) as developed by [8]. The ECM will enable us estimate the degree to which equilibrium behavior drives short run dynamics. Hence, the speed of adjustment can be ascertained. It must be noted that the existence of cointegration among the variables converges equations (3.3) to Error Correction Model (ECM) as shown below:

$$
\begin{aligned}
& \Delta^{k_{0}} \operatorname{Re} t_{t}=\beta_{0}+\beta_{1}\left(\Delta^{k_{1}} C O I L_{t-i}\right)+\beta_{2}\left(\Delta^{k_{2}} G D P_{t-i}\right) \\
& +\beta_{3}\left(\Delta^{k_{3}} I N T_{t-i}\right)+\beta_{4}\left(\Delta^{k_{4}} I N F_{t-i}\right) \\
& +\beta_{5}\left(E C M_{t-i}\right)+\mu_{t}
\end{aligned}
$$

\subsection{Estimation Techniques}

The technique used in this study involved Co-integration and Error-Correction Modeling Techniques. To estimate the
Co-integration and error correction, three steps are required: Testing for order of integration, The Co-integration test and the error correction estimation.

Unit Root Test

The unit root test involves testing the order of integration of the individual series under consideration. Several procedures has been developed for the test of order of integration such as the Augmented Dickey-Fuller (ADF) test according to [6]. Augmented Dickey-Fuller test relies on rejecting a null hypothesis of unit root (the series are nonstationary) in favor of the alternative hypotheses of stationarity. The tests are conducted with and without a deterministic trend $(t)$ for each of the series. The general form of $\mathrm{ADF}$ test is estimated by the following regression

$$
\begin{aligned}
& \Delta Y_{t}=\alpha_{0}+\alpha_{1} y_{y t-1}+\sum_{i=1}^{n} \alpha_{i} \Delta y_{i}+\mu_{t} \\
& \Delta Y_{t}=\alpha_{0}+\alpha_{1} y_{y t-1}+\sum_{i=1}^{n} \alpha_{i} \Delta y_{i}+\delta_{i}+\mu_{t}
\end{aligned}
$$

Where $Y_{t}$ is a time series $\mathrm{t}$ is a linear time trend, $\Delta$ is the first difference operator, $\alpha_{0}$ is a constant, $\mathrm{n}$ is the optimum number of lags in the dependent variable and $\mu$ is the random error term.

Cointegration Test

This is the testing of the presence or otherwise of cointegration between the series of the same order of integration through forming a cointegration equation. The basic idea behind cointegration is that, if in the long-run, two or more series move closely together, even though the series themselves are trended, the difference between them is constant.

It is possible to regard these series as defining a long-run equilibrium relationship, as the difference between them is stationary. A lack of cointegration suggests that such variables have no long-run relationship: in principle, they can wander arbitrarily far away from each other. We employ the maximum likelihood test procedure established by [13]. Specifically, if $Y_{t}$ is a vector of $\mathrm{n}$ stochastic variables, then there exists a p-lag vector auto regression with Gaussian errors of the following form: Johansen's methodology takes its starting point in the vector auto regression (VAR) of order $\mathrm{P}$ given by

$$
Y_{t}=\mu+\Delta_{1} y_{t-1}+\ldots+\Delta p y_{t-p}+\varepsilon_{t}
$$

Where $Y_{t}$ is a $n x 1$ vector of variables that are integrated of order commonly are denoted (1) and $\varepsilon_{t}$ is $n x 1$ vector of innovations.

$$
\Delta y_{t}=\mu+\eta_{y t-1}+\sum_{i=1}^{p-1} \tau_{i} \Delta y_{t-1}+\varepsilon_{t}
$$

Where 


$$
\eta=\sum_{i=1}^{p} A_{i-1} \text { and } \tau_{i}=-\sum_{j=i+1}^{p} A_{j}
$$

To determine the number of co-integration vectors; [12] and [13] suggested two statistic test, the first one is the trace test ( $\lambda$ trace). It tests the null hypothesis that the number of distinct cointegrating vector is less than or equal to q against a general unrestricted alternatives $q=r$. the test calculated as follows:

$$
\operatorname{\lambda trace}(r)=-T \sum_{i=r+1} \operatorname{In}\left(1-\hat{\lambda}_{t}\right)
$$

Where

$\mathrm{T}$ is the number of usable observations, and then $\lambda_{t}$ are the estimated eigenvalue from the matrix. The Second statistical test is the maximum eigenvalue test $(\lambda \max )$ that is calculated according to the following formula

The test concerns a test of the null hypothesis that there is $r$ of co-integrating vectors against the alternative that $r+1$ cointegrating vector.

\section{Error Correction Model}

This can be performed when cointegration is proven to exist; it requires the construction of error correction mechanism to model dynamic relationship. The purpose of the error correction model is to indicate the speed of adjustment from the short-run equilibrium to the long-run equilibrium state. The greater the co-efficient of the parameter, the higher the speed of adjustment of the model from the short-run to the long-run. Thus, the error correction model can be restated as in equation 3.5 above.

\section{Results and Discussion}

Table 1. Descriptive Statistics on Stock Market Returns and Macroeconomic Variables.

\begin{tabular}{lllll}
\hline Variables & LCOIL & LGDP & LINF & LINT \\
\hline Mean & 1.525761 & 3.706444 & 1.165396 & 1.232164 \\
Median & 1.458328 & 3.781785 & 1.098396 & 1.244751 \\
Maximum & 2.021231 & 5.106404 & 1.862343 & 1.500374 \\
Minimum & 1.115943 & 2.160862 & 0.730962 & 0.095830 \\
Std. Dev. & 0.286175 & 1.014675 & 0.304676 & 0.095582 \\
Skewness & 0.401441 & -0.188011 & 0.841996 & -0.128137 \\
Kurtosis & 1.839666 & 1.600188 & 2.782312 & -0.694328 \\
Jarque-Bera & 3.152409 & 3.326374 & 4.565097 & 3.224386 \\
Probability & 0.206758 & 0.189534 & 0.102024 & 3.132969 \\
Observations & 38 & 38 & 38 & 0.208778 \\
\hline
\end{tabular}

Note: LCOIL, LGDP, LINF LINT and RETURN represents crude oil prices, gross domestic product, inflation rate, interest rate and stock market return. Source: Author's Computation 2020

Table 1 above shows the summarized descriptive statistics computed on the series of crude oil prices, gross domestic product, inflation rate, interest rate and stock market return respectively. It is remarkable that both the median and average values are positive in each case. This means these variables displayed an increasing tendency through the period of investigation. Thus, there is statistical evidence that since the period of 38 years crude oil prices, gross domestic product, inflation rate, interest rate and stock market return have been increasing. Looking at the range of these variables, gross domestic product has the largest range (from 5.106404 to 2.160862) with an associated standard value of 1.014675 . This implies that gross domestic is the most volatile among the variables. In a different token, stock market return has the lowest range (from 0.434723 to -0.139378 ) with an associated probability value of 0.122027 and this appears to have lowest volatility. The scale of skewness with respect to gross domestic product and interest rate are -0.188011 and 0.694328 respectively. This implies that these variables are negatively skewed and as such, they exhibit large values over a long portion of the sampling period. On the contrary, crude oil prices, inflation rate and stock market return are positively skewed and have large values over a short period. The values of kurtosis that are larger than 3 show that interest rate and stock market return are leptokurtic, and therefore, they have tin tail in their distribution pattern, suggesting that there are presence of outliers or large values in the expected future date. However, while crude oil prices, gross domestic product and inflation rate are plytokurtic in nature, suggesting that there is no presence of outliers. Finally, the probability values corresponded to Jarque-Bera statistics with respect to crude oil prices, gross domestic product, inflation rate, interest rate and stock market return are larger than 5 percent. This implies that these variables are normally distributed.

\subsection{Pre-estimation Test}

In describing the underlying characteristics of the data collected on the selected variables, there is mixed results with respect to skewness, kurtosis and normality features of the variables. However, by confirming the possibility of fitting the data into vector error correction model for estimation purpose, the pre-estimation test was conducted using Philip-Peron (PP) Technique for stationarity test and correlation analysis for perfect collinearity test. Table 2 provides the summarized results of the stationarity test, while tables 3 and 4 display the correlation matrix for multi-collinearity test. 
Table 2. Philip-Peron Unit Root Test Results.

\begin{tabular}{lllll}
\hline Variable & PP-Stat & $\mathbf{5 \%}$ CV & P-Value & Integration \\
\hline DLCOIL & -5.569843 & -2.945842 & 0.0000 & I $(1)$ \\
DLGDP & -3.096661 & -2.945842 & 0.0358 & I $(1)$ \\
DLINF & -4.517538 & -2.945842 & 0.0000 & I $(1)$ \\
DLINT & -3.961143 & -2.945842 & 0.0000 & I $(1)$ \\
DRETURN & -5.18457 & -2.945842 & 0.0001 & I $(1)$ \\
\hline
\end{tabular}

Source: Author's Computation 2020

The Philip-Peron (PP) unit root test is conducted to verify the order of integration of each variable. The outputs of the test are the Philip-Peron (PP) statistics, the 5 percent critical values and probability value, which are presented in table 2. The null hypothesis here is that the series is not stationary or the series has a unit root. This hypothesis is rejected, if the ADF statistic is larger than the associated critical value at 5 percent in absolute form or the associated probability value is less than 5 percent (0.05). From the result presented, it is explicit that all the variables are stationary at first difference and this implies that they are all integrated at the same order of 1 i.e. I (1). Based on this result, the meaningful technique for estimation is Johansen multivariate cointegration method, which is adopted in the estimation section.

Table 3. Correlation Test.

\begin{tabular}{lllll}
\hline Variables & LCOIL & LGDP & LINT & LINF \\
\hline LCOIL & 1 & 0.4316 & -0.1468 & -0.4022 \\
LGDP & 0.4316 & 1 & 0.3649 & -0.2670 \\
LINT & -0.1468 & 0.3649 & 1 & 0.3006 \\
LINF & -0.4022 & -0.2670 & 0.3006 & 1 \\
\hline
\end{tabular}

Source: Author's Computation 2020

The first column of table 3 shows the correlation coefficients in-between each peer of the variables-crude oil prices, gross domestic product, interest rate and inflation. The first peer has the correlation coefficient of 0.4316 , the second has -0.1468 and the third has -0.4022 . This means crude oil prices and gross domestic product move in the same direction, while crude oil prices moves in opposite direction with inflation and interest rate. The second column shows the correlation between gross domestic product and interest rate, and between gross domestic product and inflation rate. The first peer has the correlation coefficient of 0.3649 , and the second has -0.2670 . In the first peer, the gross domestic product moves in the same direction with interest but it moves in opposite direction with inflation rate. In the third column, the correlation between inflation and interest rate is given as 0.3006 . Thus, there is evidence of weak correlation coefficients, which invariably suggests that each peer of the variables is not perfectly correlated, and as such, the assumption of multi-collinearity or perfect collinearity is refuted. Since, I have established that all the variables are I (1) and there is absence of multi-collinearity, I can now proceed to estimation tests

\subsection{Estimation Test}

The study investigated the relationship between macroeconomic variables and stock market performance. In order to examine the relationship between macroeconomic variables and stock market performance, these are subjected to long run cointegration analysis using Johansen method, error correction analysis and dynamic short run analysis. Tables 4 to 6 report the results of the analysis.

Table 4. Long Run Cointegration Test

\begin{tabular}{lllll}
\hline Hypothesized & \multicolumn{5}{l}{ Trace } & $\mathbf{0 . 0 5}$ & \\
\hline No. of CE (s) & Eigenvalue & Statistic & Critical Value & Prob. ** \\
\hline Panel A & & & & \\
None * & 0.757661 & 134.8345 & 76.97277 & 0.0000 \\
At most 1 * & 0.651998 & 83.80749 & 54.07904 & 0.0000 \\
At most 2 & 0.543790 & 35.80782 & 45.19275 & 0.0525 \\
At most 3 & 0.236364 & 17.55495 & 20.26184 & 0.1131 \\
At most 4 & 0.195853 & 7.847040 & 9.164546 & 0.0884 \\
\hline Panel B & & & & \\
\hline None * & $\mathbf{0 . 7 5 7 6 6 1}$ & $\mathbf{5 1 . 0 2 7 0 0}$ & $\mathbf{3 4 . 8 0 5 8 7}$ & $\mathbf{0 . 0 0 0 3}$ \\
\hline At most 1 * & 0.651998 & 37.99967 & 28.58808 & 0.0024 \\
At most 2 & 0.543790 & 22.25288 & 28.29962 & 0.0606 \\
At most 3 & 0.236364 & 9.707906 & 15.89210 & 0.3617 \\
At most 4 & 0.195853 & 7.847040 & 9.164546 & 0.0884 \\
\hline
\end{tabular}

Source: Author's Computation 2020

Table 4 displays the results of the trace test in panel A and maximum Eigen test in panel B. The trace value or statistic in the first row (134.8345) is larger than the 5 percent critical value (76.97277). Therefore, the null hypothesis of no cointegration is rejected. However, in the second row, the trace value (83.80749) is larger than the critical value (54.07904), meaning that the null hypothesis that there is one vector or cointegrating equation cannot be rejected. This is also confirmed by the probability value associated to both trace values which are lesser than 5 percent. In the same token, the Eigen value or statistic in the first row (51.02700) is larger than the 5 percent critical value (34.80587). Therefore, the null hypothesis of no cointegration is rejected. However, in the second row, the critical value (37.99967) is larger than the trace statistic (28.58808), meaning that the null hypothesis that there is one vector or cointegrating equation cannot be rejected. Thus, based on the trace and Eigen test there is evidence of cointegration and long run relationship between macroeconomic variables and stock market performance in Nigeria. The next important question is what is the nature of this long run relationship? In table 6, the answer to this question is provided.

Table 5. Nature of the Long Run Relationship

\begin{tabular}{lllll}
\hline Variable & Coefficient & Std-error & T-value & P-value \\
\hline LCOIL (-1) & 0.029418 & $(0.06519)$ & {$[0.45125]$} & 0.6548 \\
LGDP (-1) & -0.028353 & $(0.02098)$ & {$[-1.35158]$} & 0.1859 \\
LINT (-1) & 0.407104 & $(0.13259)$ & {$[3.07028]$} & 0.0043 \\
LINF (-1) & 0.062783 & $(0.04714)$ & {$[1.33190]$} & 0.1920 \\
C & -0.379461 & $(0.16811)$ & {$[-2.25717]$} & 0.0308 \\
\hline
\end{tabular}

Source: Author's Computation 2020

The long run coefficient with respect to crude oil prices is 0.029418 and the associated t-value 0.45125 . This means in the long run crude oil prices will increase insignificantly with 
increase in stock market performance. The long run coefficient of gross domestic is -0.028353 with associated tstatistic value of -1.35158 . This implies that in the long run the gross domestic product has a negative and insignificant impact on the stock market performance. However, the coefficient of interest rate is 0.407104 with an associated tstatistic value of 3.07028 and this reveals that interest rate has positive and significant impact on stock market performance in the long run. In addition, the coefficient of inflation rate is 0.062783 and the associated t-statistic value is 1.33190 and this implies that inflation rate is positive and insignificant impact on stock market performance in Nigeria. The disequilibrium in the long run must be corrected otherwise, long run relationship does not exist. The correction mechanism is referred to error correction model (ECM). Thus, the study estimates the ECM coefficient along with short run dynamic coefficients, and the values of these coefficients are presented in table 6 .

Table 6. Dynamic Short Run.

\begin{tabular}{lllll}
\hline Variable & Coefficient & Std-error & T-value & P-Value \\
\hline ECM & -0.801483 & $(0.23346)$ & {$[-4.63241]$} & 0.0001 \\
D (RETURN (-1)) & 0.140991 & $(0.16302)$ & {$[0.86489]$} & 0.3934 \\
D (LCOIL (-1)) & -0.208045 & $(0.18872)$ & {$[-1.10240]$} & 0.2784 \\
D (LGDP (-1)) & 3.108477 & $(0.68788)$ & {$[4.51893]$} & 0.0007 \\
D (LINT (-1)) & -0.203322 & $(0.32188)$ & {$[-0.63167]$} & 0.5324 \\
D (LINF (-1)) & -0.075423 & $(0.06874)$ & {$[-1.09717]$} & 0.2805 \\
\hline
\end{tabular}

Source: Author's Computation 2020

Table 6 uniquely presents the coefficients of short run dynamic variables- DRETURN (-1), DLCOIL (-1), DLGDP $(-1)$, DLINT (-1), DLINF (-1) and ECM coefficient. The dynamic coefficient of return and gross domestic product at lag 1 is positive. This means an increase in previous stock market performance and gross domestic product could lead to increase in current stock market performance in the short run. While previous value of crude oil prices, interest rate and inflation rate at lag 1 is negative. Hence, in the short run dynamic changes in the crude oil prices, interest rate and inflation rate could lead to negative changes in stock market performance. The ECM coefficient is -0.80 , suggesting that any disequilibrium can be corrected at the speed or rate of 80 percent within a year. In view of this, there is long run dynamic influence running from macroeconomic variables to stock market performance.

\section{Conclusion}

This paper work examined the relationship between some selected macro-economic variables on stock market performance and data were collected from C. B. N annual statistical bulletin 2018 from 1981 to 2018. The descriptive statistics was employed to examine the nature of the data. The pre-estimation test was conducted by using Philip Peron (PP) unit root test. The null hypothesis which stated that the series is not stationery or the series has a unit root was rejected since ADF statistics is greater than associated critical value at 5 percent in absolute form or probability value is less than 5 percent.

The result shows that all the variables are stationery at first difference, this implies that they are all integrated at the same order one i.e. I (1). The result also shows evidence of cointegration and long run relationship between macroeconomic variables and stock market performance in Nigeria. Furthermore, the long run coefficients of macroeconomic variables are negative and positive values and also significant and insignificant respectively.

Hence, there is disequilibrium in the long run and must be corrected otherwise, long run relationship does not exist. Therefore, the error correction model was used to correct the disequilibrium in the long run relationship. The Error Correction Model (ECM) coefficient is -0.80 suggesting that any disequilibrium can be corrected at the speed or rate of 80 percent within a year.

The finding shows that there is long run dynamic influence running from macroeconomic variables to stock market return.

\section{Recommendations}

1. In the light of the above findings, we hereby recommended that government should try more in making the data readily available after each fiscal year.

2. Government and policy makers should put in place policies to encourage industrial sector for the promotion of industrial production in order to enhance stock market performance in Nigeria. This can be achieved by increasing spending in infrastructural facilities such as power and roads and others measures such as tax holidays.

3. Government and monetary authorities should make efforts to maintain the low interest rate which will encourage investors to invest and have impact on stock market performance.

\section{References}

[1] Adam \& G. Tweneboah (2008). Do macroeconomic variables play any role in the stock market movement in Ghana? MPRA Working Paper No. 9368.

[2] Adeleke, A. I. \& A. O. Gbadebo (2012). Macroeconomic policy and returns on equities: Empirical Evidence from Nigerian Capital Market. International Research Journal of Finance and Economics, 83, 1450-2887.

[3] Anyaduba J. O., \&Idolor, E. J. (2015). Foreign Capital Flows, Financial Openness and Stock Market Volatility. Indian Journal of Economics, 96 (381), 197-238.

[4] Asaolu, T. O. \& Ogunmuyiwa, M. S. (2010). An econometric analysis of the impact of macroeconomics variables on stock market movement in Nigeria, Asian Journal of Business Management, 3 (1), 72-78.

[5] Campbell, J. Y., \&Yogo, M. (2006). Efficient Tests of Stock Return Predictability. Journal of Financial Economics, 81 (1), 21-60. 
[6] Dickey, D. A., and Fuller, W. A., (1979) "Distribution of the Estimators for Autoregressive Time Series with a Unit Root". Journal of the American Statistical Association, Vol. 74, 427431.

[7] Emmanuel, E. D. \& Samuel, O. A. (2009). An Impact Analysis of Real Gross Domestic Product Inflation and Interest Rates on Stock Prices of Quoted Companies in Nigeria. International Research Journal of Finance and Economics, 25.

[8] Engle, R. F. \& Granger, C. W. J. (1987). Cointegration and error correction representation, estimation and testing Econometrica, 55 (1), 231-276.

[9] Hsing, Y. (2011). The stock market and macroeconomic variables in a BRICS countries and policy implications. International Journal of Economics and Financial Issues, 1 (1), 12-18.

[10] Izedonmi, P. F. \& I. B. Abdullahi (2011). The effects of macroeconomic factors on the Nigerian stock returns: A sectoral approach, Global Journal of Management and Business Research, 11 (7).

[11] Jansen, M., \& Moreira, M. J. (2004). Optimal Inference in Regression Models with Nearly Integrated Regressors, Working Paper, Harvard University.

[12] Johansen, S. (1988) 'Statistical Analysis of Cointegration
Vectors', Journal of Economic Dynamics and Control, Vol. 12, pp 231-254.

[13] Johansen, S., and K. Juselius, (1990) 'Maximum Likelihood Estimation and Inference on Cointegration - With Applications to the demand for money', Oxford Bulletin of Economics and Statistics, Vol. 52, pp 169-210.

[14] Lanne, M. (2002). Testing the Predictability of Stock Returns. Review of Economics and Statistics, 84 (3), 407415.

[15] Ologunde, A. Elumide, D., \& Asaolu, T., (2006). Stock market capitalization and interest rate in Nigeria: A time series analysis. International Research Journal of Finance and Economics.

[16] Ratanapakorn, O. \& Sharma, S. C. (2007). Dynamics analysis between the US stock return and the macroeconomics variables, Applied Financial Economics, 17 (4), 369-377.

[17] Rault, C., \& Arouri, M. E. H. (2009). Oil prices and stock markets: what drives what in the gulf corporation council countries? William Davidson Institute Working Paper No. 960. Available at SSRN: http://ssrn.com/abstract $=1488936$. Retrieved January 25, 2014.

[18] Sharma, G. D., \& Mahendru, M. (2010). Impact of macroeconomic variables on stock prices in India. Global Journal of Management and Business Research, 10 (7), 1926. 